Federal Employees or Rogue Rangers: Sharing and Resisting Organizational Authority through

Twitter Communication Practices

Veronica R. Dawson

vradevadawson@csustan.edu

California State University, Stanislaus

Nicolas Bencherki

Université TÉLUQ

Montreal, Quebec, Canada

A more recent version of this article is published in Human Relations:

https://doi.org/10.1177/00187267211032944

\begin{abstract}
On January 24, 2017, the Trump administration tried to censor various science-related federal agencies, most notably, the National Park Service. This case study presents the emergence of "alternative" National Park Service Twitter accounts that subverted the ban and explores how "rogue rangers" share in and resist organizational authority through communication practices we interpret as dis/attributing communicative action to various figures to do so. Through qualitative analysis of textual and non-textual data pertaining to the accounts, we demonstrate that organizational members create ambiguity through communicative dis/attribution to do and say more things than authorized, while maintaining a link to their organization, for it is as members that their actions and words are authoritative. The study concludes by theorizing three contributions to the literature on authority and resistance, in particular in the context of social media: 1) it shows that authority and resistance are at play even outside of conventional organizations, which conversely means that social media activity can display a level of organizationality; 2) it demonstrates that the communicative performance of authority and resistance rests on membership ambiguity; and 3) it extends current conversations on the communicative performance of authority by showing that the same practices can also perform resistance.

Keywords: Authority, resistance, organizationality, organizational membership, Twitter
\end{abstract}




\section{Federal Employees or Rogue Rangers: Sharing and Resisting Organizational Authority through Twitter Communication Practices}

On the day of Donald J. Trump's inauguration as America's $45^{\text {th }}$ President in 2017, the National Park Service (NPS), the organization that manages famous parks such as Yosemite, Yellowstone, the Statue of Liberty and the Capitol Mall, tweeted out two photographs comparing Trump's inauguration festivities to those of his predecessor, Barack Obama. The Trump administration quickly caught the post, deeming it a misrepresentation, and ordered the NPS, a federal agency, to delete the offending tweet and cease social media activity for the time being. This temporary ban, which hours later extended to other federal agencies, such as the Environmental Protection Agency and the National Aeronautics and Space Administration, led to the creation of alternative Twitter accounts, which espoused relation to the silenced agencies, by rogue employees who had taken it upon themselves to tweet out banned information. Although other federal agencies were also banned from social media at the same time, we focus on the National Park Service, because the case originated with a set of official NPS tweets and thus provided for the moniker traditional media used to describe the NPS employees: "rogue rangers." The term "alternative" or "alt" was used by social media users and by traditional media outlets to describe the Twitter accounts created to continue tweeting scientific facts and information while remaining ambiguous on the actual relationship to official park accounts.

We examine the unique case of the alternative NPS Twitter accounts in order to elucidate the communicative constitution of authority and resistance. We are interested in how social media users utilize the options available to them to deal with the organizational authority placed over their activities in this context. Observing what takes place in the case of the alternative Twitter accounts, allows us to show how organizational members interactionally attribute their 
speech and actions to organizational "figures" - a generic term that designates the people, technologies, principles, rules, documents, and practices that may speak on behalf of the organization - or to other figures that are not related to the organization, in a way that at once authorizes them to speak and act on organizational behalf, and presents their speech and actions as resisting organizational authority.

We adopt a view of authority anchored in the communicative constitution of organizations (CCO) theorizing (Benoit-Barné and Cooren, 2009; Benoit-Barné and Fox, 2017). CCO views authority as a situated, interactional accomplishment, performed as individuals mobilize organizational figures and present them as sharing the authorship of their actions. For instance, it is by staging their own action as also required by organizational regulations that allows individuals to act authoritatively. Authority is thus related to the ability of guiding collective action, since any claim to act authoritatively also organizes a multitude of organizational figures into a specific configuration that is presented as sharing a particular course of action (Taylor and Van Every, 2014). Such a communicative view of authority recognizes that authority is dynamically accomplished depending on the figures being mobilized, and as individuals alternate between passivity - presenting themselves as merely acting on behalf of an organizational figure - and activity - presenting themselves as the main authors of their own actions and, thus, downplaying organizational figures (Bourgoin et al., 2020; Cooren, 2010).

A CCO perspective on authority allows us to look for it wherever communication practices take place, without presuming of a pre-existing organization. Indeed, “organizationality," i.e., whether a given collection of people constitutes an organization or not, is the result, rather than a prerequisite, of the situated, interactional accomplishment of organizational authority (Dobusch and Schoeneborn, 2015; Schoeneborn et al., 2019). In this 
sense, scholarship has suggested that, when deciding whether a market, a network, or other groups are "organizational" in nature, one should look for, among others, whether authority is present (Ahrne and Brunsson, 2011). A communicative approach to authority thus allows observing how issues of organizational authority may be at play even outside of traditional organizational sites. In this study, we make the argument that social media activity can display a level of organizationality: facilitated by the technical features of Twitter, organizational authority is mobilized via the interactional attribution of one's communicative actions (e.g., one's statements on Twitter) to a set of figures that stand-in for an organization (i.e., similar logos, matching locations, official account retweets). In sharing the action's authorship with the figures, the post's author presents it as "passive" in carrying out organizational requirements. In contrast, organizational authority is evaded by interactional disattribution of the action to a different set of figures (i.e., different hashtags, naming different organizations, dissimilar logos, explicit rejections of belonging), or by presenting oneself as "active" and thus as the sole author of the actions in question.

The remainder of the paper is organized as follows: we review the existing literature on communicative approaches to authority, noting the limited literature on the interactional accomplishment of authority and resistance in social media context; then we explain our methodology, focusing on our strategies to manage multiple social media interactions in a qualitative study. Finally, we present our analysis of the case, before discussing our contributions: 1) that social media activity, by performing authority, displays organizationality; 2) that authority and resistance rest of membership and authorial ambiguity; and 3) that authority and resistance do not contradict but rather rely on the same communicative practices. We 
conclude by inviting organizational researchers adopting a communicative standpoint to broaden their methods and to investigate social media contexts.

\section{The communicative accomplishment of authority and resistance as dis/attribution of action}

A growing number of studies suggests that organizational phenomena, including authority, are constituted through people's interactions, i.e., through the way they talk and act together (see Benoit-Barné and Cooren, 2009; Benoit-Barné and Fox, 2017). This is done by making situationally relevant various figures - any element that can be said to speak on behalf of the organization, such as a principle, a value, a document, a piece of software, an ID card, and even other people - that lend weight to their action when they are presented as sharing the authorship of that action, which is therefore a "collective" action (Bencherki et al., 2019; Bourgoin et al., 2020). This is the case, for instance, when we present a school policy as a reason to deny a request from a student or when we invoke the school's value of "excellence" to justify a hiring decision. In such cases, our action - denying a request or hiring someone - is coauthored by the school, given that it requests such a course of action through its policies and values.

\section{Performing Authority and Constituting Organizationality}

Understanding authority as the mobilization of figures means that whenever authority takes place, it is also a particular configuration of people, technologies and norms that is assembled and accepted (Taylor and Van Every, 2014). In this sense, the performance of authority contributes to the constitution of organizational reality, and there is no need to presume a pre-existing organization to witness authority taking place. On the contrary, literature on "organizationality" - i.e., how markets, networks and groups may display features of organizations - shows that authority is a key ingredient of organizations, and that wherever we 
find authority at play, we may possibly also be witnessing organizing processes (Ahrne and Brunsson, 2011; Dobusch and Schoeneborn, 2015; Schoeneborn et al., 2019).

This is crucial in theorizing authority, as it opens the possibility of looking for organizational authority outside of conventional organizational arenas (say, meetings or other work-related interactions) by directing attention away from structural features or resources, and instead towards communication practices (see Bourgoin et al., 2020). As will be evident in our case, being able to "follow" organizational authority wherever it may take place, including on social media, is all the more important at a time when literature announces post bureaucratic, boundaryless and boundary-spanning work practices, and when both control and resistance expand beyond clear organizational demarcations (e.g., Ashkenas et al., 2015). Similarly, in our case, it is precisely the ability of the National Park Service (and, ultimately, of the federal government) to reach outside of the workplace and to authorize or deny what takes place on Twitter that is at stake, raising the question of whether these online interactions display organizationality and warranting further investigation.

\section{“Mobilizing” Figures: The Dis/attribution of Action}

To further operationalize the view of authority we put forth above, we need to clarify how, through specific communicative and interactional practices, authority may be performed. So far, literature has suggested that people mobilize or draw on figures to lend weight to their actions, which may give the impression that they pick them among a pre-existing repertoire of excuses to justify what they do. Instead of this usual conception, it may be helpful to think of people interactionally attributing their actions to figures that they consider as sharing authorship of these actions. Such attributions thus make these actions recognizable as belonging to an organization. We will show that the interactional practices through which people negotiate 
authority consist in specific words, images, or other features of Twitter that mark a given action's - in particular, a tweet's - co-authorship by the focal organization (namely, the National Parks Service and its parks) or as pertaining to other entities, including individual authors.

To take a non-social media platform example, a researcher's work can be described as their own, yet when they write their university's name under their own in an article, they share authorship of the article with the university, and thus also attribute their research to the institution. This makes the researcher's writing authoritative in that it is backed by an institution - but also enables the university to claim the research as theirs. Indeed, the Dean may also compile the researcher's article as part of the college's research statistics, thus also attributing it to the institution (or, possibly, from the researcher's perspective, appropriating the work). Newspapers and third parties may report on the research findings, thus also attributing the researcher's work to the university and perhaps even erasing the individual authorship (see also Dobusch and Schoeneborn, 2015). Alternatively, if the article had turned out to be based on unethical research, the university could possibly sanction the researcher and attempt to publicly disaffiliate from him or her. But had the researcher signed their article differently - for instance, without affiliating to the university - that article's "organizationality" would be trickier to determine, and the university's ability to impose sanctions would be debatable too. Thus, considering authority as a communicative performance involves looking at the precise communicative traces through which a given action is attributed to the organization or individual author and what consequences co-authorship has in allowing specific organizational configurations and outcomes. 


\section{The Apparent Stability of Authority}

While a communicative view of authority considers it a continuous performance, i.e., no one "has" authority once and for all, the fact is that some people's (or things') authority may appear more durable or stable. Rather than viewing such stability as the intrinsic quality of some people or their position, the $\mathrm{CCO}$ literature recognizes that some attribution practices sediment into texts and technologies, such as contracts, organizational charts or computer systems (Taylor and Van Every, 2014). Going back to our hiring example, even if a professor's recruitment was controversial, once hired their authority to teach is not (usually) contested; the professor's picture goes on the departmental website, their name is on the schedule, and they are in possession of an employee ID that unlocks the classroom door and of a password to the in-class computer to load teaching materials. Thanks to these "texts" (in the broadest sense of the word), the professor does not have to establish their authority each time. Communication practices of attribution may thus become routine and act as "authoritative texts" that guide the unfolding of new situations, such as each new class the professor begins teaching (Kuhn, 2008, 2012).

However, this apparent stability of authority does not entail that everything "members" do, pertains to the organization. A communicative perspective turns upside down the usual understanding of membership: it is by attributing their actions to an organization, and when others acknowledge such attributions, that people establish their status as "contributors" and members (Bencherki and Snack, 2016; Grothe-Hammer, 2019). In that sense, when people attribute their actions to an organization, they also present the organization as sanctioning those actions and as recognizing that they are more or less faithfully acting on its behalf. The professor teaches on behalf of the university because she is a faculty member, but she is a member precisely because she is recognized - by students, by fellow faculty - as teaching on behalf of 
the university. Attribution practices at once make the organization a co-author of action, and position actors under organizational authorization. If authorization is granted, the actor may speak and act on organizational behalf or, if it is not, the actor's actions are illegitimate (Cooren, 2010). A communicative perspective on authority thus reverses the delegation model of authority, which has been critiqued as simplistic (Benoit-Barné and Cooren, 2009; Kuhn, 2008), and recognizes that, rather than receiving a mandate from the top down, we also routinely present ourselves as acting and speaking on behalf of our organization or interact with others as if they acted and spoke on organizational behalf (Lerner, 1993; Taylor and Van Every, 2014).

\section{Redefining Resistance and Compliance}

An interactional view of authority allows us to understand resistance to authority not in opposition but rather as the same set of communication practices constituting different situations and begetting different actions as a result. Resistance has been described as a set of practices, such as engaging in non-work (Paulsen, 2015), curating one's appearance (Murphy, 1998) or creating new rituals (Lawrence, 2004), that are not necessarily different from practices of compliance. As authority and resistance both stem from the same interactional practices, they do not either constitute or oppose organizational reality, but are instead jointly productive of it (Courpasson et al., 2012; Mumby, 2005). This is consistent with some of the existing literature on resistance, which suggests that it consists in people's production of alternative stories or in the reappropriating vocabulary crucial to their identity (e.g., Brown and Humphreys, 2006; Thomas and Davies, 2005). As a result of authority and resistance consisting of the same interactional practices, it is not possible to sort out ahead of time if some behaviors are "compliant" and if others are "resistive" (Del Fa, 2017; Kärreman and Alvesson, 2009; Mumby, 2005). Even seemingly resistive practices, such as using company resources for personal use, may in fact 
strengthen organizational control (Anteby, 2008). Whether a behavior is compliant or resistive, then, depends on the interaction in which people engage to perform and assess the behavior, rather than in the intrinsic nature of that behavior.

However, overt resistance to organizational authority may not always be wise or beneficial. Hence and instead, actors may carefully balance how they present their relationship to the actions they undertake, i.e., either as more passive, presenting organizational figures as the co-authors of action that authorize them to act, or as more active, by emphasizing their own authorship of the action, thus downplaying the organization's co-authorship and authority (Bourgoin et al., 2020). Rather than emphasizing their own authorship, people may interactionally dis/attribute their actions to different figures than those related to the organization in question. For instance, a university researcher giving a talk at a nearby hospital may put her university's logo predominantly on her slides and on the announcement flyer, thus attributing the talk primarily to the university and downplaying the relationship to the hospital. Such attributions may counter other attempts to attribute / appropriate the action - for instance, the researcher may stress her university affiliation in reaction to claims by the hospital director that the talk was in fact his initiative - and, therefore, the researcher's situating some actions outside of the hospital's domain of authority may constitute a form of resistance. In that sense, thinking in terms of dis/attribution recognizes that others may attempt to attribute (or not) the same actions to different figures, thus appearing, from the focal actor's perspective, as appropriation or usurpation.

\section{Accomplishing Authority and Resistance on Social Media}

While current research on authority as an interactional accomplishment has mostly studied face-to-face interaction, some research has also hinted that such practices may take place 
on social media (Albu and Etter, 2016; Gehl, 2016; Glozer et al., 2019). Online communication has been shown to be more than just a means to convey information, as exchanges over new technology and the internet also contribute to constituting organizational reality (Albu and Etter, 2016; Dawson, 2018). That being said, for the moment, research on technology in organizational settings has mostly given the impression that either it liberates people from organizational authority or that it reinforces the organization's grasp of their actions (e.g., Ajunwa et al., 2017; Pittinsky and Shih, 2004). However, online settings may reveal in a more acute manner that whether an action is organizational or not is not a given, and that authority and resistance are the outcome of concrete interactional practices. Indeed, while it may be easy to presume that any work taking place within the organization's premises is "organizational" in nature, social media makes work diffuse and the relationship between action and its author more convoluted, thus stressing the necessity to engage in attribution (Dobusch and Schoeneborn, 2015).

The interactional nature of authority (and, conversely, resistance) is made more obvious in the context of social media, because it makes the authorship of any given action less directly observable, and therefore its belonging to an organization a matter open to discussion. That may be why resisters turn to blogs to blur their organizational ties (Courpasson, 2017), and why it is so difficult to tell whether hackers operate as an organization or not (Dobusch and Schoeneborn, 2015). Indeed, anonymity hides personal identity, but also makes the authorship of action blurrier (Peddinti et al., 2014). When organizational membership cannot be easily presumed, then people must interactionally figure out whose actions are relevant to their organization (Bencherki and Snack, 2016). That is why looking for an action's "organizationality" online i.e., where it lies on a spectrum between being organizational or not (Schoeneborn et al., 2019) requires that we look for the precise practices through which attribution and appropriation of 
action are interactionally accomplished (on the notion of practice, see Gherardi, 2000). In the case of social media, this turn to practice entails that we look at how people write their posts and their profile descriptions, what pictures they use, how they retweet and like other posts, and how they use hashtags and other metalinguistic elements, as well as the way they sequence these various elements (Meredith, 2019; Tromble, 2018).

Observing authority and resistance at the level of interaction allows for the bridging of social media and organizational contexts. We find Goodwin's (2006) theorizing based on Goffman's (1981) notion of footing, to be especially relevant to Twitter. Goffman (1981) defines footing as "the alignment we take up to ourselves and the others present as expressed in the way we manage the production or reception of an utterance" (p. 128). Beyond the single utterance, we must pay attention to the way actors borrow, report, and reuse each other's speech and thus jointly co-construct social reality in their interactions and dialogue. Importantly for us, beyond the most straightforward notion of dialogue, in reported speech (i.e., quotations) a speaker incorporates in some fashion the talk of another person, but also of non-human figures (a principle, an agreement, a piece of software, etc.) to animate them. For example, participants can draw from online-specific cultural codes and technical features as figures to mobilize in their narrative accomplishment of authority or resistance (Case and Piñeiro, 2006).

In this sense, Twitter's feature to directly quote content, by "retweeting" the post of someone else from one's own account, establishes a connection between the two accounts, and co-creates a joint frame of interaction (in that both actors are linked in the interaction, which now appears to come from both). A retweet, in its form as reported speech, then helps co-construct a multi-party interaction on Twitter, and the speaker whose utterance is being reported becomes an actor through the reporting of their speech. Notably, the more a post, as an utterance, is retweeted 
on Twitter, the more widespread it becomes, its authorship becoming shared by more people. The notion of interactional footing thus allows us to connect reported speech to the way organizational authority and resistance to it are re/produced in interaction, and to demonstrate how this process uniquely plays out in the case of the alternative NPS accounts on Twitter. Adopting an interaction approach to the study of authority and resistance online, while paying attention to communication practices of attribution and disattribution, may thus reveal that ambiguity over the authorship of speech and action is not an unfortunate by-product of online conversation, but rather a core and useful feature of authority and resistance (Courpasson, 2017).

With this said, the complexities of the process of studying authority and resistance on social media must be acknowledged. In a post-truth age of fake news and misinformation campaigns developed and orchestrated to influence social media users (Carr et al., 2020), the questions of what/ who constitutes authority and whether resistance is even possible in this context, are more pertinent than ever. While some argue that social media users successfully operationalize the technology to create change through social movement (see Castells, 2015); others retort that social media technology's logic and algorithms are insidious and unbeatable, questioning their status as spaces for fruitful participatory culture (see Milan, 2015; van Dijck and Poell, 2013). We acknowledge both sides of this argument. We recognize the case examined here as an instance of social protest and advocacy utilizing the available features of the social media context for those purposes. Our methodology and analysis are also sensitive to the fact that social media are not neutral and merely designed to facilitate interaction, that carefully crafted algorithms reveal and obscure the data and the very processes we aim to study, including the communicative constitution of authority, resistance, and organizationality. 
Based on the literature above, we ask: How do organizational members use figures to interactionally dis/attribute their speech and actions to share in or resist organizational authority?

Our analysis focuses on the practices, through which alternative accounts dis/attribute their utterances, images and other posted content to the corresponding official parks and figures (such as logos, locations, images, and staff) or to other entities and figures (such as the \#resist movement, the public's right to knowledge, or a poster's identity as a private citizen). Our findings show how the alternative Twitter accounts at once attribute or disattribute their tweets to NPS figures and to other, non-NPS figures, even within a single tweet. We contend that it is this balancing act that allows the alternative accounts to continue their educational mission by sharing the NPS' authority, while also positioning themselves as not subjected to its restrictions.

\section{Method}

\section{Case setting}

In addition to the events of January 20, 2017, when Donald J. Trump was inaugurated as the $45^{\text {th }}$ President of the United States on the Capitol Mall in Washington, DC (see Table 1 for timeline of the case's main events), the official Twitter account of Badlands National Park (@BadlandsNPS) , $^{\mathrm{i}}$ in South Dakota responded to the ordered social media blackout by going rogue and shared a sequence of climate change related tweets concerning carbon dioxide in the atmosphere and ocean acidity. The posts remained on Twitter for hours but were eventually deleted later that day. National Park Service officials explained that the Badlands account was "compromised" by a former employee, thus actively disassociating the NPS and the particular park from the rogue activity and blaming it on an outsider with unauthorized access to the Badlands' Twitter account. 


\section{INSERT TABLE 1: TIMELINE OF EVENTS ABOUT HERE}

Within hours, in support of the silenced National Park Service and @BadlandsNPS, a number of "alternative" Twitter parks accounts emerged and began posting scientific and environmental information within the content domain of the original NPS entities. The word alternative - or the "alt" that prefixed some of the Twitter account names - was attributed to a play on the phrase "alternative facts" used by the Trump administration to justify the claim that Trump's inauguration was better attended than Obama's, although all evidence pointed to the contrary. Thus, when we call the unauthorized NPS accounts that emerged on Twitter in January 2017, "alternative," we are simply using the common parlance by which these accounts were referred to by themselves and third parties (e.g., Twitter users, traditional media).

\section{Data Collection Strategy}

Aligned with our conceptualization of authority, resistance, and interaction, based on the observation of concrete communication practices, we focused our efforts on identifying and carefully describing key activities within limited number of posts and comments. Limitations were set by the case's timeframe and at the time, the relatively small number of posts by "alt" accounts. In our analysis, we further limit the number of examples presented to allow for an indepth look at the complex interactional practices at play. We conducted the analysis in a threestep process, inspired by Toffoletti and Thorpe (2018) and: 1) collected and analyzed all posts made by the 14 accounts in the span of 7 days, 2) collected and analyzed comments to these posts from the first visible comment, continuing until we reached a "saturation point," and 3) randomly scrolled into the comments to check whether any other themes emerged. 
We collected data from 14 accounts, which we found by using the "Advanced Search" feature of Twitter and searching for the accounts publicized in news media between the dates of January 24 and January 31, 2017. We chose the dates based on 1) when the original Badlands National Park tweets occurred (which led to the creation of the first "alternative" account) and 2) the end of the first week of tweeting, by which point some of the account owners had begun transferring them to non-NPS-affiliated entities. We manually recorded the Twitter posts and captured visuals from the alternative National Park Service accounts by going through each account's page and feed (see Table 2 for a side-by-side list of NPS Twitter accounts, corresponding "alternative" Twitter accounts, followers, and number of tweets collected per alternative account). To gain as comprehensive understanding of the phenomenon as possible, our data collection encompassed Twitter posts (tweets), retweets, mentions, replies, and hashtags posted by the 14 accounts, which we collected by scrolling down to the bottom of each account's feed where one finds the earliest posts and moving "up" to the latest. In addition, we collected account names, handles, bios, and profile photos from the accounts' pages. In accounts where links were part of the bio, we followed the links and noted the website information we found. In the period of 7 days, we collected 519 tweets across the 14 accounts.

\section{INSTERT TABLE 2: LIST OF ACCOUNTS ABOUT HERE}

\section{Analytical Strategy}

Social media in general and Twitter in particular are not typical data collection sites for scholars focusing on the detailed study of communication practices (for exceptions, see Albu and Etter, 2016; Dawson, 2018; Kavada, 2015, 2016). Such scholarship often adopts utterance-based 
methods such as conversation analysis and speech-act analysis, as well as other forms of analysis of communication events. That being said, some research has applied these methods to social media: Dobusch and Schoeneborn (2015) for example, studied the hacktivist collective Anonymous ethnographically, utilizing "identity claims analysis" (Vaast et al., 2013) of communicative episodes, communicative events, and speech acts (i.e., identity claims) performed online. Similarly, we align our theoretical framework and our research interest in the communicative constitution of authority and resistance as accomplished in social media context and investigate communicative events, such as utterances and text, in the context of specific Twitter posts and accounts. To accomplish this, we performed a textual analysis of the social media data we collected (Kavada, 2015), including Twitter posts (tweets), replies, retweets, visuals, and tagging. In our reading of the tweets, we specifically focused on identifying communication practices of attribution and disattribution of action (i.e., of what was said and done in the posts), as well as the organizational figures to which dis/attribution was performed.

Driven by our theoretical framework, we analyzed the collected data iteratively (Miles et al., 2020), shifting our attention between what the data revealed and the concepts we sought to engage with. We used the constant comparative method (Charmaz, 2001) in coding the data and adopted two units of analysis: 1) textual markers (words, hashtags, retweets) and 2) extra-textual elements (visuals, logos, photographs). In addition to being units of analysis, these textual markers and extra-textual elements also materialize and make available various organizational figures to other Twitter users. In respect to these figures, an author on Twitter interactionally either attributed authority to the NPS (thus remaining passive) or, on the contrary, disattributed authority by attributing communicative action not to the NPS (thus actively authoring). Attribution and disattribution were also interactionally performed by "external" authors (other 
social media users). For example, we recognized attribution, as a second-level code, through the following first-level codes: logos similar by structure, composition or color to those of the real organization, or tweets where pictures of specific parks were posted in alternative accounts (on how visual branding elements contribute to organizational constitution, see Vásquez et al., 2013). In written posts, we recognized attribution when authors noted "commonality" by calling themselves "rangers" or made references to "we," "us," and "ours" while speaking of the real organization. We recognized external attribution when others would ascribe "ranger identity" to the account owners or when an assumption of organizational belonging would otherwise be demonstrated, as in user posts tagging both the alternative and real park. Disattribution (secondlevel code), in contrast, was recognized when alternative accounts would adopt logos highlighting "dissimilarity" (first-level code) to the originals, would post disclaimers (i.e., "nongovernment employee run"), or would state in a post that they have "transferred control" of the account to non-NPS employees.

\section{Methodological Limitation}

A methodological limitation in a case entirely contained within Twitter is presented by the very context. Some argue that Twitter's algorithms are powerful non-human actors that exert agential control over user and researcher experience alike (Lange et al., 2019; Neyland, 2015); yet others proclaim that various actors enact algorithms differently and through this enactment gain agency (Seaver, 2017). We recognize that the context and the data we engage with in this study may be obfuscated by algorithmic power, making it difficult to guarantee that despite our best efforts described above, the interactions we have collected and analyzed in this case have not been influenced by algorithmic design. By collecting all tweets and replies posted by the 14 "alt" accounts, we do not know whether we missed other interactions elsewhere, or how they 
might have unfolded had algorithms been different, but we at least know that we captured what was visible to us.

\section{The Rogue Rangers of Twitter}

The alternative Twitter accounts and their authors mobilized various figures in order to communicatively attribute or disattribute authority and resist to the National Park Service. We identified five dis/attributive communication practices utilizing such figures: the choice of visual appearance, the inclusion of meta information, the use of hashtags (\#), the wording of internally authored posts (i.e., those created by the account), and the wording of externally authored posts (i.e., those created by others in relation to the account) (see Table 3). We order the practices according to the layout of a Twitter account, or what a user would see first when looking at an account's page, starting at the top and moving downward.

\section{INSERT TABLE 3: DIS/ATTRIBUTIVE COMMUNICATION PRACTICES \&}

\section{FIGURES}

\section{Accomplishing Authority Through the Dis/attribution of Action in Visual Appearance}

Twitter, like other social media, allocates space for a profile picture, which serves as a primary identifier. In Twitter, this is the image associated with an account and is displayed both on the account's page and along any post or comment made by the account. The National Park Service and all individual parks share the same profile picture - the NPS logo, an arrowhead enclosing a mountain peak, a sequoia, a lake, and a bison on a brown background with the words "National Park Service" inscribed within. Logos are some of the most easily identifiable organizational figures both internally and externally. It is not surprising that the NPS logo 
becomes one of the most obvious ways through which the alternative accounts share or reject NPS authority.

The alternative accounts attribute communicative action to the NPS by demonstrating pride in the original logo. For example, pride is observable in an interaction about the original NPS logo between a follower's posts and a retweet / response by @NotAltWorld (formerly @ALTNatParkSer) on January 25, 2017: “@JordanGracey With all of the @AltNatParkSer stuff going on, we ought to take a moment to appreciate how beautiful their logo is too. [image of the NPS logo]” “@NotAltWorld Sequoia tree \& bison represent vegetation/ wildlife, mountains represent scenic values, \& the arrowhead represents our archeological values" (italics added). In this interaction, the "alt" account shares authority by suggesting belonging to the NPS, first, via the explanation of the meaning behind the original logo's elements, demonstrating intimate knowledge of the NPS and its values; and second, through the possessive pronoun "our," which identifies the account authors as agents belonging to, knowing, and representing the NPS. The alternative Twitter accounts split in their use of the NPS logo as an organizational figure-some adopted a version of it highly resembling the original; others created logos that were very dissimilar. With this said, all alternative park accounts had an individualized profile picture, which borrowed elements of the original NPS logo (see Table 4).

INSERT TABLE 4: ATTRIBUTIVE LOGOS ABOUT HERE 
The three logos demonstrate a clear similarity: they all include a snowy mountain, at least one tree, an animal silhouette, and a palette of green and orange-brown. This imagery makes it difficult not to perceive passivity - the accounts are presenting themselves as acting on behalf of the original NPS account, even if by a form of parody. There are, though, clues as to the alternative accounts' desire to distinguish from the official one too. Notably, despite the identical color scheme between the original and alternative logos, the @ AltNPS logo is a raised fist, which is congruent with the alternative accounts' activity - presenting themselves as authors of their own actions, namely as "The Resistance," often through the \#resist hashtag, which we find in visuals and in the accounts' descriptions.

The @AltUSNPS and @ AltNPS are two accounts that have gone through transformations demonstrating the ambiguity associated with the attribution and disattribution of their actions to the NPS. Upon the accounts' creation, the two actually bore the logo of the "real" National Park Service, pictured on the far left in Table 4, an attributive move suggesting their affiliation to the organization by sharing a clearly identifiable figure. However, two days after the inception of the case, on January $26^{\text {th }}$, @ AltUSNPS announced a new logo (middle image) in a tweet, citing legal concerns over the appropriation of the NPS's organizational logo: "Big thanks to @ AngelaStaehling for designing our new logo! Enough to not get sued and retains the spirit of the \#rogueranger founders!" The authors actively disattribute the logo figure from the NPS due to fears of impending authoritative action, yet this post is simultaneously an attributive move in that it is accepting of a donated image created by one of the long-term artist collaborators of the National Park Service and by establishing an explicit link to the account's founders and their identity as (rogue) rangers. As a result, the communication coming from @ AltUSNPS remains ambiguous, allowing for the flexibility to both reject belonging (by 
adopting a different logo) and claim authority (by collaborating with NPS approved artist and mobilizing the ranger identity).

Other accounts chose to visually mark a distinction from their federal counterparts (see Table 5), and therefore not to use logos to establish an attributive link.

\section{INSERT TABLE 5: DISATTRIBUTIVE LOGOS ABOUT HERE}

A logos' role as a practice of disattribution is particularly obvious in the case of @NotAltWorld, an account that changed ownership within a few days of its creation and whose logo and account name bear no resemblance to the original NPS logo or alternative versions. The account changed its handle and logo once the @ AltNatParkSer account announced switch in ownership — from government employees, to non-government employees, with disattribution occurring immediately after the ownership change on January $26^{\text {th }}$. The other two logos pictured here, however, made no such ownership announcement and logo change - they started out with dissimilar or disattributive logos. Thus, it is fair to conclude that as an organizational figure, the logo has a complicated role in the case of the NPS's alternative accounts. Even though in traditional forms of organizing the logo is the most recognizable and promoted organizational image, in the context of this case, logos act more ambiguously. Clearly, a similarity between alternative and original logos may suggest connection, the logo alone isn't sufficient to allow for unquestionable authority sharing. Combined with other organizational figures, such as metainformation, which we review next, the communicative practice of attribution, and the sharing of authority that it implies, become more obvious. 


\section{Accomplishing Authority Through the Dis/attribution of Action in Meta-Information}

Along with a profile picture, every Twitter account provides space, outside of an account's tweets, for what we call meta-information, such as its description, location, founding date, web links, and number of followers / following. For the alternative accounts, this metainformation revealed several attribution and disattribution practices with respect to both official organizational figures and different figures.

In terms of attributive practices, @ AltNPS claims to be "The official 'Resistance' team of the U.S. National Park Service" (italics added) in the account's description. The word "official" functions to suggest authority, shared at once with the NPS and with the \#resist movement, which spurred the alternative accounts in January 2017. The account provides a link to a website (altnps.org) that further identifies its creators as part of the NPS and thus, clearly presents the account as speaking on the agency's behalf:

Our resistance started with Badlands National Park. ... The Trump administration has been attempting to deconstruct our agency. Our members have joined together to resist the Trump administration (italics added).

Below this statement, as members and co-signatories, are listed nearly all major NPS parks, such as the Grand Canyon National Park, Mount Rainier National Park, Sequoia National Park and Yosemite National Park. The statement announces membership with the expression "our agency," referring to the National Park Service as a whole. Such irrefutably attributive moves are rare and are notable because they clearly identify the account as belonging both to the NPS and to a group of alternatives, thus highlighting an ambiguity over speech and action authorship remaining to be interpreted by social media users. 
The communicative effect of ambiguity over authorship is especially evident when alternative Twitter accounts struggled between attribution and disattribution in their metainformation. @ AltYelloNatPark's descriptive statement provides an example where the tension is palpable: "Locked = blocked. An unofficial group of employees, scientists \& activists, in \& around Yellowstone national park. Fighting Rapid Global Climate Change, everyday” (italics added). The description serves both attributive and disattributive functions, both rejecting the authority to speak on behalf of Yellowstone and sharing in it. First, the account's owners note that they are "unofficial," which distinguishes their account from the actual Twitter for Yellowstone National Park (Twitter verifies popular accounts as "official" by the denotation of a blue dot and a checkmark). However, the word "employees" clearly points to organizational membership and further affiliation is implied through the location, "in \& around Yellowstone national park." Interestingly, this account provides a web link to a fundraising website (defendourparks.org), where further dis/attribution takes place through a mission statement written in bold:

We're going after the politicians who are going after our national parks. Why? Because the National Park Service mandate doesn't allow park employees to engage in a political fight. This leaves our parks defenseless against greedy corporate politicians. So, we created the all-volunteer organization Defend Our Parks, a licensed Super Pac registered and ready to rumble. We are going to do a little campaigning of our own.

Based on the information provided through this link, it seems obvious that the people behind the alternative Yellowstone account do not act in their capacity as NPS employees, which is reinforced by the account description, which denotes the authors ambiguously as "unofficial 
employees." Yet, the association appears in the possessive pronoun "our" when referring to the parks and in the Defend Our Parks' mission statement, which identifies the group as "allvolunteer organization," dedicated to raise funds for parks preservation. The National Park Service as an organization is predicated on volunteer help. According to 2020 NPS data, the agency reported 15,426 permanent employees, including administrators, operations, cultural resources, and rangers. By comparison, "a diverse pool of roughly 221,000 annual volunteers contribute incalculably to hundreds of parks" (Hansen, 2015: 220). Volunteers participate in nearly every aspect of the agency's functioning. Hence, the "all-volunteer" identifier remains ambiguous in terms of organizational affiliation and in terms of whether these particular volunteers can "speak" in association with, if not on behalf of, the parks and the NPS.

The ambiguity of the account's description and linked website represents the tensions within the dis/attribution of communicative action and the tension's effect on the action's positioning with respect to organizational authority. In the above example, @ AltYelloNatPark both shares and refutes the NPS's organizational authority by both/ and dis/attributing communicative action to the effect of co-constructing a productive ambiguity over authorship (are the authors employees or volunteers, and of what organization exactly?). Authority and resistance, thus, appear to be the product of the same ambiguous action. In their use of hashtags, however, Twitter accounts are more direct in identifying with an organized resistance movement and attributing their actions and statements to it.

Accomplishing Authority Through the Dis/attribution of Action Through Hashtags (\#)

A hashtag is a word or a phrase preceded by a hash sign (\#), used in social media to identify posts on a specific topic. Twitter users use hashtags to follow and contribute to conversations using the same hashtag (for instance, they would use \#BLM to identify posts 
related to the Black Lives Matter movement). The 14 alternative accounts we studied used hashtags in meta-information and in posts. Placing hashtags within meta-information (bios/ account description) may be a way of making sure that the account is found, not just its individual posts. Placing a hashtag in a post, in addition to linking it to other posts on the same topic, may also function as reported speech, allowing the author to enter an ongoing interaction on Twitter and thus contribute to co-constructing it, by bringing into their post the views and positions expressed by others using the hashtag. Hashtags were used to dis/attribute action to entities, whether to the NPS or to \#resist and \#altgov collectives.

Alternative accounts used hashtags in meta-information to attribute communicative action to figures different than the NPS and aligned with the resistance to organizational (governmental) authority. For example, the accounts @NotAltWorld, @ AltNatParkSer, @AltHVNP, and @NastyWomenofNPS all used the hashtags \#TheResistance and \#resist, identifying them as accounts belonging to the Twitter resistance movement that formed in the wake of Trump's social media gag orders. A typical account description looked like this one by @ AltUSNPS, which is especially notable because it contains the \#RogueRanger, to mark attribution to the (rogue) ranger identity, in addition to \#Resistance:

Alt US National Park Service \#RogueRanger \#Resistance movement. Climate change exists. No drilling in National Parks. Take Action and Make a Difference. By placing the hashtags in their profiles and posts, the accounts share in the NPS's authority, but also in that of a collective of accounts recognized on Twitter solely by the two resistance-related hashtags. In this sense, \#TheResistance, in particular, appears to attribute the accounts, and therefore their posts, to the collective movement, and therefore to present them as acting on its authority. Similarly aligned with resistance is another often used hashtag, \#altgov, 
pointed to a different diffused Twitter collective - that associated with other censored governmental agencies (i.e., NASA, the EPA, and even the White House). By using \#altgov in their account descriptions, some "alt" NPS accounts attributed their communication to the resistive alternative government represented on Twitter, thus delineating their actions and communication from the National Park Service's authority.

Alternative accounts used hashtags to attribute communicative action also within their Twitter posts. Hashtags attribute communicative action to a specific topic, and in "alt" account posts, the topic reliably related to the NPS. For example, @ BadHombreNPS shares authority with the official @BadlandsNPS when communicating scientific information related to the park: "\#alternativefact of the day: clean coal is a real thing. \#climate @BadlandsNPS". In fact, @BadHombreNPS tags @ BadlandsNPS in posts 8 times on January $24^{\text {th }}$ alone, utilizing the additional hashtags \#oceanacidification, \#notalternativefact, and \#facts. Importantly, some of the alternative accounts also retweeted screen shots the offending and now deleted @BadlandsNPS tweets within their own posts, which used an extensive number of hashtags to link to various other interactions. For example, @ AltLassenVolcanicNP retweeted screenshots of the whole sequence of posts on January $26^{\text {th }}$, including its own highly relevant at the time hashtags \#climate, \#climatefacts, \#science, and directing them to @ RealDonaldTrump and @ POTUS. Tagging Trump's Twitter accounts and utilizing some of the most popular hashtags of the week, thrust the alternative account in a public and polarized forum replete with information about the National Park Service.

Using relevant hashtags ensures that the author contributes to the appropriate Twitter interaction while sharing authority with others utilizing the same hashtags. In terms of dis/attribution, this allows an alternative account to simultaneously attribute a communicative 
action both to the official account (Badlands NPS), and to a series of hashtags that caused the sanctioning of the official account in the first place, thus actively authoring against authority and resisting censorship. As a communicative practice, hashtags function as reported speech in interaction, animating organizational (original NPS account) and alternative (sanctioned \#) figures. Although in our interpretation hashtags are attributive in their very purpose as figures of Twitter, they can certainly attribute communicative action differently, including to a movement conceived as resistance to government institutions, including the NPS, thus implying disattribution.

Finally, we turn to the Twitter posts - both those authored "internally" by the alternative NPS accounts and those authored "externally" by the media and public. The next two sections offer a deeper look into the posts constituting the account for the Alternative National Park Service on Twitter. We chose to focus on a specific account due to the vibrancy of the data it provides. While the movements we identify within this account were not uncommon for others, and are missing the retweeting of NPS content we observed in other accounts, the Alternative National Park Service account was an original, which underwent important and informative changes in just three days.

Accomplishing Authority Through the Dis/attribution of Communicative Action in Internally

\section{Authored Posts}

The @AltNatParkSer account, later renamed to @NotAltWorld, published several posts on January $24^{\text {th }}$, the day of inception for the accounts covered in this case. On that day, the posts were clearly attributive to NPS figures and to the agency's employees - the authors' "brothers and sisters@BadlandsNPS.” A series of foundational tweets reveal the various organizational 
figures towards which attributive communication was carried out, illustrating the desire and authority to speak on behalf of a park:

1. "Hello, we are the Alternative National Park Service Twitter Account activated in time of war and censorship to ensure fact-based education."

2. "Tonight Trump gagged National Park Services [sic] \& signed executive order to restart Dakota Access \& Keystone XL pipelines. \#climate”

3. "Shoutout to the anonymous crews at @ BadlandsNPS continuing the great work of the original before Trump's (tiny) hand came down."

4. "Respect goes out to our brothers and sisters at the @ BadlandsNPS. When they silence you, we will speak for you" (italics added).

The four posts, all from the evening of January $24^{\text {th }}$, refer to figures such as the National Park Service (first post) and the original rogue account of Badlands National Park (third and fourth posts), especially by addressing the rangers at Badlands as brothers and sisters in the third tweet and, of course, by giving them credit for originating the climate tweets that spurred the Trump administration to react. In doing so, the authors attribute their account and its posts to the NPS and its employees, and present themselves as communicating under their authority. Importantly, the account owners indicate official identity in the first tweet, which was in response to a user question, and outline their mission in the final tweet by proclaiming that they "will speak for" the silenced government accounts (and employees). While the first three tweets establish a relationship with the NPS, the fourth tweet is particularly attributive in its strong identification with the rogue rangers of Badlands NP and the act of speaking on their (and the park's) behalf. 
The four tweets also reference recent historical facts that help place them in Twitter and news media discourses at the time, ensuring that audiences attribute @ AltNatParkSer communication as part of the resistance (and in this way, also disattribute it from the official NPS). For example, mentioned are the National Park Service and the issue of censorship, but also controversial environmental issues, namely the Dakota and Keystone oil pipelines, protests against which had started at the end of the Obama presidency and were continuing at the time. These mentions, and the \#climate, tie the account to interactions surrounding climate issues by suggesting the pipelines are the reason for censoring Badlands National Park, which is geographically nearby. Of note is also the humorous reference to Trump's hands, which at the time trended under the \#tinyhandsoffpubliclands hashtag circulated on Twitter in early 2017 along with public land advocacy posts. By using sanctioned hashtags and communicating about controversial events, such as censored climate and environmental information, @AltNatParkSer on one hand, disattributes its communication from the official agency. On another hand, the tweets attribute communicative action to the NPS by promising to continue to speak for the Service and thus, continue the organization's educational mission.

Notably, the Alternative National Park Service account on Twitter also spent time explaining its values and mission, meaningful organizational figures in themselves, beyond the aforementioned desire to speak on behalf of its "brothers and sisters." In doing so, the tweets openly and repeatedly attribute these values and mission, and by implication the account's action and statements, to the NPS and the rangers working for the agency:

1. "Here is the DL on the National Park Service. Most of us are in the job to one reason. We LOVE our outdoors. It IS the greatest." 
2. "We take immense pride in keeping the parks clean and safe for all Americans and tourists from around the world."

3. "Park ranygers [sic] come from all walks of life. Some have escaped the city \& others never left the mountains. But we have one yuuuge common goal."

4. "Our job is to preserve the natural \& cultural resources \& values of the National Parks System for enjoyment, education, and inspiration.”

5. "To understand what's best for our parks, we need to have access to US science data on climate \& the environment. We must not be silenced."

The five tweets first identify the writers as rangers and then present an effectual mission statement that resembles, and in some places almost entirely copies, that of the National Park Service. By nearly copying the NPS's mission statement, the authors of the alternative account share in the official organization's authority. Indeed, in the first tweet, the authors identify themselves as working for the NPS. The emotions, boldly expressed in the tweets, are congruent with descriptions of the forest rangers' pride, fondness and keen knowledge of their districts and of their job, as well as with the high organizational identification found among forest rangers (see Connie Bullis' work). The third tweet provides more insight into the rogue rangers behind @ AltNatParkSer and makes a mocking reference to Trump and the inaugural crowds by misspelling the word "huge" as "yuuuge."

However, by January $26^{\text {th }}$ the attention around the rogue rangers appeared to have become too risky for the Alternative National Park Service, which switched strategy and opened the day with a series of dis/attributive tweets starting with: "We have decided to pass over control to individuals outside of government employment for the sake of our colleagues." As with previous dis/attributive communicative action, this post performs both disattribution in the 
figurative passing of control, and attribution to a different entity (non-governmental), after implying that the current owners are employees, and stating that the handover is done in the name of colleagues who are presumably also government employees. After acknowledging the successes from the previous days, and perhaps because of the media's frantic attempts to uncover the identities behind the anonymous alternative accounts, @AltNatParkSer notes: "But we cannot escape the pressure that the popularity of this account has brought to our colleagues. It is selfish to continue ourselves." Again, the authors claim belonging as "colleagues" and, "as such, we are handing the control of this account to several activists \& journalists who believe that they can continue in the same spirit," the tweets continue, suggesting that the account was not managed by activists nor journalists to this point. And now that it will be managed by others, those others are authorized by the NPS employees to speak in their name.

Because of the refusal to unambiguously identify as rogue rangers, the owners of this and other alternative accounts became subjected to Twitter users' and media speculation attempting to resolve for their anonymity. We have already demonstrated that the ambiguity mobilized by the alternative accounts as far as the rogue rangers' identity goes assists in the sharing of authority with the NPS. In the final section of the analysis, we demonstrate that dis/attributions of communicative action to the NPS (or other entities), and hence, the constitution of authority and resistance, are as dynamic when accomplished by outsiders. Accomplishing Authority Through the Dis/attribution of Communicative Action in External Posts

As various Twitter users and media attributed posts by the alternative accounts to the NPS or to other organizations, interactions on Twitter read like a mystery novel focused on ascribing identity to the anonymous rogue rangers as (un)authorized organizational representatives. Interactions between the alternative accounts and Twitter users demonstrate that 
when organizational membership can’t be easily presumed, interactants must figure out whose actions are relevant to the organization's mission. We identify three entities that dis/attribute communicative action to the alternative accounts: the public (private citizen's Twitter accounts), the news media, and other alternative Twitter accounts.

Public dis/attributions. The public engaged in attributive practices by posting images, GIFs, memes, and written posts and linking them to the alternative accounts by tagging (@X) them. Attribution may be seen in the vigorous response @ AltNatParkSer received when, on January $24^{\text {th }}$, it called for: "Tweet us pics from your last visit to a US national park. Rangers love feedback. Even if they can't officially tweet it back now." This tweet generated 2,800 responses, 2,400 retweets, and 8,800 reactions. The public posted about their visits to parks and tagged both the alternative account and the official park account: "On our road trip, we popped into Petrified Forest National Park b/c my kids love science \& facts. @ AltNatParkSer @ NatlParkService” (@ christiemegill). By tagging both the alternative account and the official park, this user attributes an existing relationship between the two. The follow-up post from @ AltNatParkSer accepts the attribution and tags the official NPS account and shares on its authority: "We are a bit overcome by how many of you are tweeting us pictures of your visits to @ NatlParkService. Thank you for supporting the service." The alternative account mobilizes a number of organizational figures to attribute authority: it adopts an educational ranger voice by requesting photos of park features, tags an official account, hence including its authors in the interaction, and thanking users on behalf of the service.

Tweets celebrating the alternative accounts, as if they were official, attribute communicative action as well: “Shout out to@AltNatParkSer and @BadHombreNPS for carrying the torch and fighting censorship re: @ BadlandsNPS \#ResistTrump \#Climate" 
(@SarahStierch). Here an official park, the original rogue Badlands account, is mentioned along two alternative accounts, while authority is outright given to the alternative accounts by pronouncing them torch carriers of the organizational mission. Others celebrated the rise of the alternative accounts and did so through their digital connection with the originals: "NPS! NPS! NPS! Heroes! @ BadlandsNPS @DeathValleyNPS @ AltNatParkSer”(@ MeganNormy). In this tweet, the NPS, two of its parks, and one alternative are brought together, suggesting that all are authors of "heroic" action and, therefore of equal authority. The public also effectively ascribes the ranger identity, a recognizable, uniformed organizational figure, to an alternative account: “\#Follow@AltNatParkSer these guys are on the frontline of \#ResistTrump and are risking their livelihood to get the facts out!” (@ ces614). These examples show that the public easily attributed communication by the alternative accounts (asking for pictures, defending facts and science, resisting censorship, etc.) to NPS employees (rangers in particular) and had little doubt about the organizational belonging of both the posts and the identities behind them.

Media dis/attributions. It was a journalist who broke the National Park Service inauguration story on Twitter and put the parks' alternative accounts under heavy media attention. On January $24^{\text {th }}$, a Twitter user notes that, “@AltNatParkSer grew its following by over 9,000 in 2 hours" ( @ PeaceandRhythm) and by January $26^{\text {th }}$, followership approached a million people, triple that of the official NPS Twitter account. These numbers were not only impressive to the public, but also newsworthy as media ranging from the National Public Radio, and New York Magazine to CNN, the Boston Globe and the Washingtonian intently covered the accounts.

The media were particularly interested in verifying the identities behind the alternative accounts. Some, like Slate, issued a call asking the accounts to contact the publication's tip line. 
Others presumably directly contacted the accounts, which is evident in this tweet posted by @ AltNatParkSer on January 25 $5^{\text {th: }}$ "We've had a lot of media attention. We've been asked by a few to identify ourselves. Be gentle with us. It's a scary climate out there.” The tweet, the reported media interest, conveyed concern and vulnerability, and even the ambiguous reference to "scary climate," implicitly attribute the author's identity as "organizational" and thus, grant it authority, suggesting that at least some alternative accounts, including @ AltNatParkSer, were managed by actual rogue rangers.

Dis/attributions by alternative accounts. The alternative accounts themselves dis/attribute their own, but also each other's communicative action to the NPS or to different figures. These dis/attributions appear in the forms of tags (@X). For example, one of the first alternative park accounts, @BadHombreNPS tagged @BadlandsNPS repeatedly in posts to attribute organizational authority to its own tweets: “Hey friends. Here to support @BadlandsNPS with the science and facts they can no longer share!" Once the Twitter connection between the accounts was achieved (and a series of more tweets followed), other alternative accounts connected with@BadHombreNPS as well, supposedly seeing it as authoritative by virtue of it repeatedly tagging the official Badlands account. In a response @ NotAltWorld (formerly @ AltNatParkServ) tweeted a greeting: "Hey ho! @BadHombreNPS” and asked the account to write to them privately, "so that we can coordinate."

The interaction between alternative accounts in itself appears attributive in that they authorize themselves as speakers for the parks and members of the larger communities of alternative accounts encompassed by the \#resist and \#altgov collectives. For example, @ AltLassenNPS sends a birthday greeting to both Rocky Mountain National Park and its alternative account, in one tweet: "Happy birthday to our beautiful neighbor @RockyNPS and 
@AltRockyNPS!" The tweet exemplifies an equal treatment between the official and alternative Twitter account and attributes a shared authority to both. In the first week of the case, the 14 alternative accounts tagged each other in few "shout outs" like the birthday greeting and the call to coordinate above. While not frequent, the tags between alternative accounts suggest a sense of coordinated action that certainly could have developed further beyond the scope of this case.

\section{Discussion}

The case of the alternative NPS accounts on Twitter shows that organizational authority and resistance to it are intertwined in the communication practices by which actors attribute and disattribute communicative action (i.e., Twitter posts) to the organization through its various “figures" - its Twitter account name, its logo, its mission, its members' professional identity, and so forth. Alternatively, they may dis/attribute their posts to others, for instance to the \#resist movement. By dis/attributing communicative action, actors may share in organizational authority to legitimize their own actions and thus position themselves as speaking on behalf of the organization and its mission, while also evading this same authority, which might have silenced them. Our analysis makes at least three contributions to the literature on authority and resistance, in particular in the context of social media. First, it shows that authority and resistance are at play even outside of conventional organizations, which conversely means that social media activity can display a level of organizationality. Second, our analysis shows that the communicative performance of authority and resistance rests on membership ambiguity. Third, and as we have already hinted in elaborating our theoretical framework, it extends current conversations on the communicative performance of authority by showing that the same practices can also perform resistance. 


\section{The Organizationality of Social Media Resistance}

Dobusch and Shoeneborn (2015) have shown that organizing can occur outside of organizations, including on social media, through the way individuals attribute their actions to a common collective. We extend their insight by further specifying that such attributions also establish authority, which Ahrne and Brunsson (2011) identified as a key ingredient to organizationality. This means that social media activity not only makes organizational boundaries more porous (Albu and Etter, 2016), but can create organizing outside of the formal organization.

In our case, this was necessary given that the official organization's core mission of disseminating scientific and environmental information was silenced by government. The alternative accounts took it upon themselves to pursue this mission, but had to do so outside of the official organization or risk being silenced too. The balance between acting on behalf of the organization, and thus sharing in its authority, and yet remaining outside of its boundaries, was accomplished by carefully enlisting various organizational figures, such as mission statements, logos, park locations, and organizational identities (i.e., being a "ranger"), but also other figures such as the \#resist movement, parody logos, and other alternative accounts. In line with the idea that authority is situationally accomplished through the dual processes of "activation" and "passivation" of human, material and abstract allies (Bourgoin et al., 2020), our analysis shows that the alternative accounts situationally adjusted the authority they accomplished to respond to each situation, by dis/attributing their actions to different organizational figures.

By assembling these various figures in adaptable ways, the alternative accounts thus displayed organizationality, but did not merely reproduce the NPS (in which case they would have been subject to its authority, and censored), nor did they entirely reject it, since they are in 
fact very much attached to it - or to what it used to be. Instead, they created a new hybrid organization (Ashcraft, 2001; Wilhoit and Kisselburgh, 2019), that was an "alternative" to what the NPS had become, as the "alt" prefix suggests. We observed such hybridization, among others, in the posts of the Alternative National Park Service account, whose organizationality draws at once on a mission statement like that of the NPS and on a stated goal to fight against censorship, thus combining two goals for collective action.

Social media was already described as a context where organizational authority is achieved through continuous interaction (Dawson, 2015). However, research in that sense had mostly focused on the difficulty for organizations to maintain control over social media activity, exemplified most recently in coffee-house giant Starbucks' contemplation to leave Facebook over "hateful comments" (Mac and Lytvynenko, 2021; see also Dawson, 2018; Sweetser and Kelleher, 2016). Our analysis shows that organizational authority does not only serve to control what is written on social media, but may in fact be used to resist the organization and pursue an alternative version of its mission, one that employees and other constituents favor. Organizational authority becomes appropriated by others and turned into a key factor in constituting a different organization, that of the resistance.

\section{Authority and Resistance Through Membership Ambiguity}

The context of social media also made salient another feature of such platforms: anonymity (Peddinti et al., 2014). In our analysis, anonymity uniquely contributes to the complexity of the communicative constitution of authority, resistance, and organizationality, by making even more relevant the ambiguity over authorship of the accounts and of their communicative actions. Such ambiguity is at the heart of the communicative constitution of organization, given that "scaling up" from situated interactions to organizational action occurs 
thanks to the possibility of describing a given action as co-authored by the organization (Castor and Cooren, 2006; Kuhn, 2012; Vásquez et al., 2018).

The practices of dis/attribution also take advantage of such ambiguity: had each action, such as a post, clearly pertained to an author, it would not be possible to attribute them to another figure (Courpasson, 2017 also shows how ambiguity over authorship is crucial to resistance). Being able to speak in the organization's name and sharing in its authority thus supposes some level of blur over the authorship of a given message or action. This problematizes the notion of membership, which often assumes that everyone who is "in" the organization acts on its behalf, as if members always faithfully carry out their organization's intentions (Bencherki and Snack, 2016; Grothe-Hammer, 2019). Our analysis shows that the accounts and the people behind them at once presented themselves as speaking for the NPS (and its mission) and yet such speech was possible because they did not quite "belong" to it. They were rogue rangers: rangers and yet rogue.

The case of the alternative Twitter accounts allows us to see how individuals negotiate their relationship with their organization (and others) and thus oscillate between claiming to speak with the authority lent by the organization (by attributing their speech to it), for instance via the ranger identity, or distancing from it to act with more independence, for instance by affiliating with the \#resist movement. Such ambiguity is also demonstrated when account owners reveal themselves as organizational members who tweet in their free time; or when identity as an employee is both confirmed and denied in the same post; or when tagging both official and unofficial accounts.

In this sense, our analysis aligns with research suggesting that the actions of people outside of the formal organization, even without membership status, can indeed be 
"organizational" and contribute to the constitution and action of the organization (Bencherki and Snack, 2016; Dobusch and Schoeneborn, 2015) and that they can reappropriate organizational figures (Albu and Etter, 2016; Etter et al., 2017). We extend this research by showing, first, that rather than thinking in terms people being either members or non-members, it may be more useful to think in terms of each action being attributed or not to the organization. Second, we show that ambiguity may be crucial to the possibility of acting, leading to membership ambiguity being cultivated, rather than incidental.

The crucial nature of ambiguity was revealed, in our case, when the pressure to deanonymize an account, especially by traditional media, led its rogue ranger authors to feel it was impossible to continue cultivating the ambiguity required to simultaneously share in and evade the authority of the NPS, thus giving up control over the account (and authorizing others to speak on their behalf). That being said, such verification by traditional media could also confirm organizational membership and, thus, affirm the account's authority. For instance, past our data collection timeframe, on June 1, 2017, the online publication Snopes circulated a list of "verified" alternative accounts. The Snopes article contained a list of 35 alternative accounts that were allegedly confirmed to be related to government employees. Some of the verified accounts in this case published links to the list and showed some pride in being revealed to be actual NPS employees. For instance, @NastyWomenofNPS, an account supposedly led by female NPS rangers and whose handle mocks another Trump expression, pinned the Snopes tweet containing a link to the article at the top of their feed, while @AltMtRainier, linked to the Snopes article in place of organizational website in their bio. While such revelation of the authors' identity might be dangerous, we may suppose it also strengthened their authority both as NPS employees and as resisters, since it confirmed that they had taken the risk to oppose their employer. 


\section{Performing Both Authority and Resistance Through Attributive Communication Practices}

The context of social media allows observing how individuals contribute to organizational action without the presumption of employment. In that sense, it shifts the power dynamics involved in organizational constitution, but also reveals to the researcher that to establish authority, resistance, and organizationality, the actual identity of the rogue rangers while it spurred fascination and contributed to cultivating ambiguity - matters less than the communicative practices through which they dis/attributed their actions to the real organization or to alternatives. Organizational authority and employee resistance are not opposed but, rather, consist in attribution of action to different entities, thus locating action under one entity's authority or not.

Hence, attribution and disattribution are not options to choose from, but rather result from the same communicative practices that we have identified: selecting an account logo, writing a description, employing hashtags and writing posts. This finding may clarify the apparent contradiction of recent studies that suggest that resistance takes place through compliance, or that attempts at resistance may in fact strengthen organizational control (Anteby, 2008; Ashcraft, 2016; Ybema and Horvers, 2017). Far from being surprising, resistance and compliance walk hand in hand because they rely, concretely, on the same communicative practices of dis/attribution. Such a communicative view contrasts with the conventional theorization of resistance as a specific set of actions and behaviors carried out in reaction to authority (for a review, see Thomas and Davies, 2005).

Through communication, organizational figures and those relating to resistance are both materialized on the same plane, and can thus be confronted, but also assembled into new, generative configurations (Ashcraft et al., 2009; Cooren, 2018; Kuhn et al., 2017). 
Communicative practices of dis/attribution can keep those two sets of figures in a productive (both/and) tension, thus accomplishing authority and resistance at once. Communication thus reveals that there is no contradiction (i.e., opposing speech) in people both appearing to authoritatively speak for the organization, which is otherwise silenced, and resisting the authority that might silence them (see also Putnam et al., 2016). It is the same "speech" that allows the alt accounts to be "authoritative" but also to free themselves from organizational authority.

Our findings thus clarify the communicative dynamics that substantiate authority and resistance. They show, on one hand, that when people invoke figures that lend weight to their actions, as suggested by interactional literature on authority (Benoit-Barné and Cooren, 2009; Benoit-Barné and Fox, 2017), they are in fact attributing their actions to those figures and placing them under their authority. In other words, the analytical relationship should be reversed. This reversal allows specifying, on the other hand, that when people tell alternative stories or engage in non-work, for instance, what they are doing is also disattributing (or reappropriating) their actions from organizational authority and resisting appropriation (Paulsen, 2015; Vaara and Tienari, 2011). Thinking in terms of attribution of action thus allows a symmetrical analysis of authority and resistance, which leads to considering their complementarity rather than opposition in organizing (thus aligning with Mumby, 2005).

\section{In Conclusion: An Invitation for More CCO Studies of Social Media Contexts}

In this article, we observed and analyzed a case that occurred entirely on Twitter. In doing so, we used types of data that are not typically associated with research on authority and resistance, nor with organizational research using interactional and communicative perspectives. Our study thus illustrates the relevance, especially for the communicative constitution of 
organizations $(\mathrm{CCO})$ tradition, of paying attention to communicative practices beyond the usual focus on text and conversation in face-to-face situations (Nathues et al., 2020; Wilhoit, 2016).

While the study of social media phenomena within interactional and communicative scholarship is still rare (exceptions being Albu and Etter, 2016; Dawson, 2018), it continues to rely mostly on texts, such as posts, replies, retweets, and account descriptions. Our study answers to recent calls to broaden what communication means and to collapse the discourse / materiality distinction (Cooren, 2015, 2020), and shows that much can be gained by analyzing metainformation of different nature (visuals, websites, and locations), and Twitter communication practices such as the use of hashtags or tagging. We open up the communicative scene further by including third parties such as the news media coverage of Twitter activity, to reveal their participation in the constitution of authority, resistance and organizationality (see also BenoitBarné et al., 2019).

Indeed, while the interaction-based methods have been reluctant to include "context" in their analysis too hastily, social media blurs the distinction between what should be considered as talk and what forms the context of talk (see Bartesaghi et al., 2019). By adopting a resolutely communicative approach to authority and resistance that does not limit communication to a particular understanding, our case study revealed how organizing a movement to denounce censorship supposed both sharing in organizational authority and resisting it. This was done by cultivating ambiguity over organizational membership and communicative action authorship. Our study revealed that the same communicative practices sustained both authority and resistance.

By studying a case taking place on Twitter and showing how authority took place in the activity we observed, we also showed that organizationality can take place on social media. Our 
research thus encourages more organizational scholars to investigate social media contexts not as a separate technological space (although it supposes its distinct affordances; see Treem and Leonardi, 2013), but rather as a continuity of what takes place in "real" organizations. As the Covid-19 pandemic revealed, social media is all the more relevant in the context of changing technology, and as organizational action is taken up and continued across actors and geographies the traditional markers of organizational membership and identity become less easily discernable (Hassard and Morris, 2021; Trittin-Ulbrich et al., 2021). As the very nature work and organization is shifting, so we must also shift our methods and theorizing.

\section{Acknowledgements}

The authors would like to thank the three reviewers and the Associate Editor, who tirelessly provided constructive criticism to make this manuscript better. We would also like to thank Dr. Alan Zemel and Dr. Alexandra (Lexa) Murphy for their helpful and encouraging feedback.

\section{Funding}

There are no funders to report for this submission.

\section{References}

Ahrne G and Brunsson N (2011) Organization outside organizations: the significance of partial organization. Organization 18(1): 83-104. DOI: 10.1177/1350508410376256.

Ajunwa I, Crawford K and Schultz J (2017) Limitless Worker Surveillance. California Law Review 105: 735-776.

Albu OB and Etter M (2016) Hypertextuality and Social Media: A Study of the Constitutive and Paradoxical Implications of Organizational Twitter Use. Management Communication Quarterly 30(1): 5-31. DOI: 10.1177/0893318915601161.

Anteby M (2008) Identity incentives as an engaging form of control: Revisiting leniencies in an aeronautic plant. Organization Science 19(2): 202-220. DOI: 10.2307/25146175. 
Ashcraft KL (2001) Organized dissonance: Feminist bureaucracy as hybrid form. Academy of Management Journal 44(6). Academy of Management: 1301-1322. DOI: $10.5465 / 3069402$.

Ashcraft KL (2016) Resistance through consent?: Occupational identity, organizational form, and the maintenance of masculinity among commercial airline pilots. Management Communication Quarterly 19(1): 67-90. DOI: 10.1177/0893318905276560.

Ashcraft KL, Kuhn T and Cooren F (2009) Constitutional amendments: "Materializing" organizational communication. The Academy of Management Annals 3(1): 1-64. DOI: 10.1080/19416520903047186.

Ashkenas R, Ulrich D, Jick T, et al. (2015) The Boundaryless Organization: Breaking the Chains of Organizational Structure. Hoboken: Wiley.

Bartesaghi M, Livio O and Matte F (2019) The authority of the "broader context": What's not in the interaction? In: Bencherki N, Matte F, and Cooren F (eds.) Authority and Power in Social Interaction: Methods and Analysis. New York, NY: Routledge, pp. 18-36. DOI: $10.4324 / 9781351051668-7$

Bencherki N and Snack JP (2016) Contributorship and partial inclusion: A communicative perspective. Management Communication Quarterly 30(3): 279-304. DOI: $10.1177 / 0893318915624163$.

Bencherki N, Matte F and Cooren F (eds.) (2019) Authority and Power in Social Interaction. Routledge studies in communication, organization, and organizing. New York, NY: Routledge. 
Benoit-Barné C and Cooren F (2009) The accomplishment of authority through presentification: How authority Is distributed among and negotiated by organizational members. Management Communication Quarterly 23(1): 5-31. DOI: 10.1177/0893318909335414.

Benoit-Barné C and Fox S (2017) Authority. In: Scott CR and Lewis L (eds.) The International Encyclopedia of Organizational Communication. Hoboken, NJ: Wiley, pp. 1-13. DOI: 10.1002/9781118955567.wbieoc011.

Benoit-Barné C, Marsen S, Wang N, et al. (2019) Decentering the analysis: The authority of spectators, journalists and others. In: Bencherki N, Matte F, and Cooren F (eds.) Authority and Power in Social Interaction: Methods and Analysis. New York, NY: Routledge, pp. 117-137. DOI: 10.4324/9781351051668-7.

Bourgoin A, Bencherki N and Faraj S (2020) “And who are you?”: A performative perspective on authority in organizations. Academy of Management Journal 63(4): 1134-1165. DOI: 10.5465/amj.2017.1335.

Brown AD and Humphreys M (2006) Organizational identity and place: A discursive exploration of hegemony and resistance. Journal of Management Studies 43(2): 231-257. DOI: 10.1111/j.1467-6486.2006.00589.x.

Carr PR, Cuervo Sanchez SL and Daros MA (2020) Citizen engagement in the contemporary era of fake news: Hegemonic distraction or control of the social media context? Postdigital Science and Education 2(1): 39-60. DOI: 10.1007/s42438-019-00052-z.

Case P and Piñeiro E (2006) Aesthetics, performativity and resistance in the narratives of a computer programming community. Human Relations 59(6). SAGE Publications Ltd: 753-782. DOI: 10.1177/0018726706066853. 
Castells M (2015) Networks of Outrage and Hope: Social Movements in the Internet Age. Second edition. Cambridge, UK: Polity Press.

Castor T and Cooren F (2006) Organizations as hybrid forms of life: The implications of the selection of agency in problem formulation. Management Communication Quarterly 19(4): 570-600. DOI: 10.1177/0893318905284764.

Charmaz K (2001) Grounded theoryy. In: Emerson RM (ed.) Contemporary Field Research. Prospect Heights, IL: Waveland Press, pp. 335-352.

Cooren F (2010) Action and Agency in Dialogue: Passion, Ventriloquism and Incarnation. Amsterdam/Philadelphia: John Benjamins.

Cooren F (2015) In medias res: communication, existence, and materiality. Communication Research and Practice 1(4): 1-15. DOI: 10.1080/22041451.2015.1110075.

Cooren F (2018) Materializing communication: Making the case for a relational ontology. Journal of Communication 68(2): 278-288. DOI: 10.1093/joc/jqx014.

Cooren F (2020) Beyond entanglement: (Socio-) materiality and organization studies. Organization Theory 1(3): 1-24. DOI: 10.1177/2631787720954444.

Courpasson D (2017) Beyond the hidden/public resistance divide: How bloggers defeated a big company. Organization Studies 38(9): 1277-1302. DOI: 10.1177/0170840616685363.

Courpasson D, Dany F and Clegg S (2012) Resisters at work: Generating productive resistance in the workplace. Organization Science 23(3): 801-819. DOI: 10.1287/orsc.1110.0657.

Dawson VR (2015) “Who are we online?” Approaches to organizational identity in social media contexts. The Journal of Social Media in Society 4(2): 28-72. 
Dawson VR (2018) Fans, friends, advocates, ambassadors, and haters: Social media communities and the communicative constitution of organizational identity. Social Media + Society 4(1): 1-11. DOI: 10.1177/2056305117746356.

Del Fa S (2017) The embodiment of the alternative: a communicational and constitutive approach of an "alternative university." Tamara: Journal for Critical Organization Inquiry 15(3-4): 219-236.

Dobusch L and Schoeneborn D (2015) Fluidity, identity, and organizationality: The communicative constitution of anonymous. Journal of Management Studies 52(8): 10051035. DOI: 10.1111/joms.12139.

Etter M, Ravasi D and Colleoni E (2017) Social media and the formation of organizational reputation. Academy of Management Review 44(1): 28-52. DOI: 10.5465/amr.2014.0280.

Gehl RW (2016) Power/freedom on the dark web: A digital ethnography of the Dark Web Social Network. New Media \& Society 18(7): 1219-1235. DOI: 10.1177/1461444814554900.

Gherardi S (2000) Practice-Based Theorizing on Learning and Knowing in Organizations. Organization 7(2): 211-223. DOI: 10.1177/135050840072001.

Glozer S, Caruana R and Hibbert SA (2019) The never-ending story: Discursive legitimation in social media dialogue. Organization Studies 40(5): 625-650. DOI: 10.1177/0170840617751006.

Goffman E (1981) Forms of Talk. Philadelphia, PA: University of Pennsylvania Press. Goodwin C (2006) Interactive footing. In: Holt E (ed.) Reporting Talk: Reported Speech in Interaction. Cambridge, UK: Cambride University Press, pp. 16-46.

Grothe-Hammer M (2019) Membership or contributorship? Managing the inclusion of individuals into organizations. In: Ahrne G and Brunsson N (eds.) Organization Outside 
Organizations. 1st ed. Cambridge, UK: Cambridge University Press, pp. 84-112. DOI: $10.1017 / 9781108604994.004$.

Hansen H (2015) Prophets and Moguls, Rangers and Rogues, Bison and Bears: 100 Years of the National Park Service. Seattle, WA: Mountaineers Books.

Hassard J and Morris J (2021) The extensification of managerial work in the digital age: Middle managers, spatio-temporal boundaries and control. Human Relations. DOI: 10.1177/00187267211003123.

Kärreman D and Alvesson M (2009) Resisting resistance: Counter-resistance, consent and compliance in a consultancy firm. Human Relations 62(8). SAGE Publications Ltd: 1115-1144. DOI: 10.1177/0018726709334880.

Kavada A (2015) Creating the collective: social media, the Occupy Movement and its constitution as a collective actor. Information, Communication \& Society 18(8). Routledge: 872-886. DOI: 10.1080/1369118X.2015.1043318.

Kavada A (2016) Social movements and political agency in the digital age: A communication approach. Media and Communication 4(4). 4: 8-12. DOI: 10.17645/mac.v4i4.691.

Kuhn T (2008) A Communicative Theory of the Firm: Developing an Alternative Perspective on Intra-organizational Power and Stakeholder Relationships. Organization Studies 29(8-9): 1227-1254. DOI: 10.1177/0170840608094778.

Kuhn T (2012) Negotiating the Micro-Macro Divide: Thought Leadership From Organizational Communication for Theorizing Organization. Management Communication Quarterly 26(4): 543-584. DOI: 10.1177/0893318912462004. 
Kuhn T, Ashcraft KL and Cooren F (2017) The Work of Communication: Relational Perspectives on Working and Organizing in Contemporary Capitalism. New York, NY: Routledge.

Lange A-C, Lenglet M and Seyfert R (2019) On studying algorithms ethnographically: Making sense of objects of ignorance. Organization 26(4). SAGE Publications Ltd: 598-617. DOI: $10.1177 / 1350508418808230$.

Lawrence TB (2004) Rituals and resistance: Membership dynamics in professional fields. Human Relations 57(2): 115-143. DOI: 10.1177/0018726704042924.

Lerner GH (1993) Collectivities in action: Establishing the relevance of conjoined participation in conversation. Text \& Talk 13(2): 213-246. DOI: 10.1515/text.1.1993.13.2.213.

Mac R and Lytvynenko J (2021) Facebook is worried Starbucks will delete its page over hateful comments. BuzzFeed News, 6 May.

Meredith J (2019) Conversation Analysis and Online Interaction. Research on Language and Social Interaction 52(3). Routledge: 241-256. DOI: 10.1080/08351813.2019.1631040.

Milan S (2015) When algorithms shape collective action: Social media and the dynamics of cloud protesting. Social Media + Society 1(2): 1-10. DOI: 10.1177/2056305115622481.

Miles MB, Huberman AM and Saldaña J (2020) Qualitative Data Analysis: A Methods Sourcebook. Fourth edition. Los Angeles: SAGE.

Mumby DK (2005) Theorizing resistance in organization studies: A dialectical approach. Management Communication Quarterly 19(1): 19-44. DOI: 10.1177/0893318905276558. Murphy AG (1998) Hidden transcripts of flight attendant resistance. Management Communication Quarterly 11(4): 499-535. DOI: 10.1177/0893318998114001. 
Nathues E, van Vuuren M and Cooren F (2020) Speaking about vision, talking in the name of so much more: A methodological framework for ventriloquial analyses in organization studies: Organization Studies. DOI: 10.1177/0170840620934063.

Neyland D (2015) On organizing algorithms. Theory, Culture \& Society 32(1). SAGE Publications Ltd: 119-132. DOI: 10.1177/0263276414530477.

Paulsen R (2015) Non-work at work: Resistance or what? Organization 22(3): 351-367. DOI: $10.1177 / 1350508413515541$.

Peddinti ST, Ross KW and Cappos J (2014) “On the internet, nobody knows you're a dog”: A Twitter case study of anonymity in social networks. In: Proceedings of the Second ACM Conference on Online Social Networks, New York, NY, USA, 2014, pp. 83-94. DOI: $10.1145 / 2660460.2660467$.

Pittinsky TL and Shih MJ (2004) Knowledge Nomads: Organizational Commitment and Worker Mobility in Positive Perspective. American Behavioral Scientist 47(6): 791-807. DOI: 10.1177/0002764203260210.

Putnam LL, Fairhurst GT and Banghart S (2016) Contradictions, dialectics, and paradoxes in organizations: A constitutive approach. The Academy of Management Annals 10(1): 65171. DOI: $10.1080 / 19416520.2016 .1162421$.

Schoeneborn D, Kuhn TR and Kärreman D (2019) The communicative constitution of organization, organizing, and organizationality. Organization Studies 40(4): 475-496. DOI: $10.1177 / 0170840618782284$.

Seaver N (2017) Algorithms as culture: Some tactics for the ethnography of algorithmic systems. Big Data \& Society 4(2):1-12. DOI: 10.1177/2053951717738104. 
Sweetser KD and Kelleher T (2016) Communicated commitment and conversational voice:

Abbreviated measures of communicative strategies for maintaining organization-public relationships. Journal of Public Relations Research 28(5-6): 217-231. DOI: 10.1080/1062726X.2016.1237359.

Taylor JR and Van Every EJ (2014) When Organization Fails: Why Authority Matters. New York, NY: Routledge.

Thomas R and Davies A (2005) Theorizing the micro-politics of resistance: New public management and managerial identities in the UK public services. Organization Studies 26(5): 683-706. DOI: 10.1177/0170840605051821.

Toffoletti K and Thorpe H (2018) Female athletes' self-representation on social media: A feminist analysis of neoliberal marketing strategies in "economies of visibility." Feminism \& Psychology 28(1): 11-31. DOI: 10.1177/0959353517726705.

Treem JW and Leonardi PM (2013) Social media use in organizations: Exploring the affordances of visibility, editability, persistence, and association. Annals of the International Communication Association 36(1): 143-189. DOI: 10.1080/23808985.2013.11679130.

Trittin-Ulbrich H, Scherer AG, Munro I, et al. (2021) Exploring the dark and unexpected sides of digitalization: Toward a critical agenda. Organization 28(1): 8-25. DOI: $10.1177 / 1350508420968184$.

Tromble R (2018) Thanks for (actually) responding! How citizen demand shapes politicians' interactive practices on Twitter. New Media \& Society 20(2): 676-697. DOI: $10.1177 / 1461444816669158$. 
Vaara E and Tienari J (2011) On the narrative construction of multinational corporations: An antenarrative analysis of legitimation and resistance in a cross-border merger. Organization Science 22(2): 370-390. DOI: 10.1287/orsc.1100.0593.

Vaast E, Davidson EJ and Mattson T (2013) Talking about technology: The emergence of a new actor category through new media. MIS Quarterly 37(4): 1069-1092.

van Dijck J and Poell T (2013) Understanding social media logic. Media and Communication 1(1). 1: 2-14. DOI: 10.17645/mac.v1i1.70.

Vásquez C, Sergi V and Cordelier B (2013) From being branded to doing branding: Studying representation practices from a communication-centered approach. Scandinavian Journal of Management 29(2): 135-146. DOI: 10.1016/j.scaman.2013.02.002.

Vásquez C, Bencherki N, Cooren F, et al. (2018) From 'matters of concern' to 'matters of authority': Reflecting on the performativity of strategy in writing a strategic plan. LongRange Planning 51(3): 417-435. DOI: 10.1016/j.lrp.2017.01.001.

Wilhoit ED (2016) Ventriloquism's methodological scope. Language Under Discussion 2(1): $45-49$.

Wilhoit ED and Kisselburgh LG (2019) The relational ontology of resistance: Hybridity, ventriloquism, and materiality in the production of bike commuting as resistance. Organization 26(6): 873-893. DOI: 10.1177/1350508417723719.

Ybema S and Horvers M (2017) Resistance through compliance: The strategic and subversive potential of frontstage and backstage resistance. Organization Studies 38(9): 1233-1251. DOI: $10.1177 / 0170840617709305$. 


\section{Biographies}

Veronica R. Dawson is Assistant Professor of Communication Studies at the California State University, Stanislaus. Her research interests reside at the intersection of organizational communication and social media with focus on the communicative performativity of organizational identity, branding, member identification, corporate social responsibility and organizationality. Dawson's work has been published in Management Communication Quarterly, Social Media + Society, and Critical Studies in Media Communication among others, and has been regularly presented at conferences, such as the International Communication Association, the National Communication Association, and the Western States Communication Association. [Contact email: vradevadawson@ csustan.edu]

Nicolas Bencherki is Associate Professor at the Université TÉLUQ. His research adopts an ethnographic approach to study organizational communication among community-based organizations, in particular when it comes to collaboration between groups to achieve collective action. Theoretically, his work explores the notions of property and possession of action, and its sharing between persons and organizations. By recognizing that property is not limited to its legal format, it is possible to empirically observe the multiple ways the organization, as well as the persons that populate it, attribute, appropriate, give, borrow, etc., the work and the activities that make the organization act and, indeed, exist as an entity. Nicolas Bencherki's work has been published, among others, in Management Communication Quarterly, Journal of Communication, and Communication Research and Practice, and was regularly presented, including at the International Communication Association and at the annual conference of the European Group for Organizational Studies.

\footnotetext{
${ }^{\mathrm{i}}$ Due to the public nature of Twitter, we refer to all organizations and accounts by their actual
} names. 